\title{
Production of Probiotic Biomass (Lactobacillus rhamnosus IS9) against Salmonella sp for Use as a Feed Supplement in Poultry
}

\section{Bertrand Tatsinkou Fossi $^{1^{*}}$, Ekue Nathalia Bonjah ${ }^{1}$ and Robert Ndjouenkeu ${ }^{2}$}

${ }^{1}$ Department of Microbiology and Parasitology, Faculty of University of Buea, PO Box 63, Buea, Cameroon

${ }^{2}$ Department of Food Science and Nutrition, National School of Agro-industrial Sciences (ENSAI), University of Ngaoundere, POBox 63, Ngaoundere, Cameroon *Corresponding author

\section{A B S T R A C T}

The occurrence of antibiotic resistant Salmonella is one of the major threats to the poultry

Keywords

Probiotics,

High cell density, antibiotic-resistant

Salmonella,

Poultry industry.

Article Info

Accepted:

15 May 2017

Available Online:

10 June 2017 industry. The use of probiotic strains is a promising alternative for the control and eradication of Salmonella in poultry. This study aims at producing and assessing the potential of Lactobacillus rhamnosus (IS9) strain to reduce Salmonella enterica serovar Enteridis and Typhimurium common in poultry. Pathogen-free chicks were orally administered by gavage with $1.0 \times 10^{9} \mathrm{CFU} / \mathrm{ml}$ of Lactobacillus rhamnosus (IS9) suspended in $0.1 \mathrm{ml}$ of sterile water and $24 \mathrm{~h}$ later were challenged in separate experiments with $S$. Enteritidis and $S$. Typhimurium. There was a significant reduction $(\mathrm{P}<0.05)$ in $S$. Enterisdis and $S$. Typhimurium in the small intestine of infected birds. The action of $L$. rhamnosus (IS9) was more important in 14-days old chicks. Salmonella count was nil in duodenum, colon and caeca of 14-days old chicks pre-dosed with a single dosed of $L$. rhamnosus (IS9). Weekly analysis of caeca swabs of chicks pre-dosed with L. rhamnosus (IS9) showed significant reduction $(\mathrm{P}<0.05)$ in Salmonella while the caeca population of lactobacilli increases.

\section{Introduction}

Probiotics are microorganisms whose administration in adequate quantities is beneficial to humans and animals (Wang et al., 2012). The probiotic properties are numerous, they can vary from one strain to another and include the inhibition of the proliferation of pathogens in the digestive tract, immunomodulation, blood regulation of sugar and cholesterol, the positive effect against certain cancers, enzymatic activities useful for humans and animals metabolism, such as phytase, amylase etc.
(Zhou et al., 2010; Zuccotti et al., 2015; Zuccotti et al., 2008; Zwolinska-Wcislo et al., 2006). Different types of microorganisms are used as probiotic strains, but strains of lactic acid bacteria are preferable because of their GRAS (Generally Regarded as Save) status (Zivkovic, 1999). The World Health Organization (WHO) and Food Agricultural organization (FAO) particularly have recommended the use of strains of probiotic lactic acid bacteria in both animal and human nutrition (Amara \& Shibl, 2015). 
Previous work carried out by La Ragione et al., (2004) and Mappley et al., (2011) reported the potential of some of these strains to reduce or inhibit the proliferation of pathogenic strains such as Salmonella sp responsible for salmonellosis in poultry. Studies carried out by Wouafo et al., (2010) and Nzouankeu et al., (2010) in Cameroon revealed a high prevalence of antibiotic resistant Salmonella in poultry farming around Yaounde the capital city of Cameroon. In addition, work by Akoachere (2009) reported a significant prevalence of Salmonella in foods of animal origin in Buea, the capital city of the South West Region of Cameroon. Moreover, the treatments offered are based on antibiotics. This intensive use of antibiotics led to the occurrence of resistant Salmonella strains (Kilonzo-Nthenge et al., 2013). The presence of these Salmonella in food products is a major public health problem and is still relevant in Cameroon (Nzouankeu et al., 2010). Very little research has been devoted to the probiotic approach to overcome the occurrence of antibiotic resistant strains in poultry farming in Cameroon. The addition of probiotic strains to animal feeding could be an effective alternative for Salmonella control.

The efficacy of a probiotic depend on the microbial strain used and mostly on the number and viability of microorganisms present in the probiotic formulation (Coeuret et al., 2004a). The important production of a viable probiotic biomass is a key step in probiotic formulation. To minimize the cost of fermentation in probiotic production, some cheaper media have been developed such as whey-based medium supplemented with ammonium salt and low level of yeast extract (0.25 g/l) (Mondragon-Parada et al., 2006).

This research work aims at developing a cheaper and efficient method of production of probiotic biomass (Lactobacillus rhamnosus IS9) and evaluate its effectiveness in the proliferation of Salmonella $s p$. during poultry farming in Cameroon.

\section{Materials and Methods}

\section{Source of microorganisms}

The probiotic strain Lactobacillus rhamnosus (IS9) was provided by the microbiology unit of Research foundation for Tropical Diseases and Environment (REFOTDE), Buea, Cameroon. This strain was previously characterized for its ability to considerably inhibit some pathogenic strains (Tatsinkou et al., 2017). This strain was thus selected in accordance with our previous results, showing the probiotic potential of some lactic strains isolated from palm wine. The pathogenic strain Salmonella enterica serovar Enteridis and Salmonella enterica serovar Typhimurium was provided by the microbiology Unit of REFOTDE. These strains are resistant to chlortetracycline and erythromycin mostly used in poultry in Cameroon.

\section{Preparation of fermenting medium}

The medium used for probiotic biomass production was molasses-based medium. The molasses samples were obtained from the sugar production company in Cameroon (SOSUCAM). The crude molasses thus obtained was diluted by adding distilled water to have a final concentration of about $2 \%$ $(w / v)$. Then the soybean was added to have a final concentration of $0.5 \%(\mathrm{w} / \mathrm{v})$ in soybeans. It was subsequently filtered to remove the solid particles by means of a Whatman filter paper (Sigma). In a $1000 \mathrm{ml}$ Erlen Meyer series, $500 \mathrm{ml}$ of the fermentation media thus prepared were introduced and then sterilized at $121{ }^{\circ} \mathrm{C}$ for 15 minutes.

\section{Preparation of inoculum}

The inoculum was prepared using pure colonies of the L. rhamnosus (IS9) strain. 
This strain was grown in de Man Rogosa and Sharpe (MRS) broth (Oxoid, Basingstoke, UK). The identification of this strain was confirmed by the use of phenotypic methods which include morphological characterization, the use of API 50 CHL (bioMérieux, France) identification kit. The colony PCR based on the amplification of 16 rDNA was also used to confirm the identity of the strain. Pure colonies of the L. rhamnosus (IS9) strain were seeded in $100 \mathrm{ml}$ of MRS broth contained in $250 \mathrm{ml}$ conical flasks and incubated in a rotary shaker at $150 \mathrm{rpm}$ for 24 $\mathrm{h}$ at $35^{\circ} \mathrm{C}$. The lactic acid bacteria colonies in the inoculum were counted by pour plate method on the MRS agar (Oxoid, Basingstoke, UK). The viability of the cells in the inoculum was observed by microscopy after staining of the cells with methylene blue. This examination of the viability of the cells was based on the fact that during the staining of cells by methylene blue, the living cells remain colorless, while the dead cells are colored blue.

\section{Fermentation Experiment}

The fermentation for the production of probiotic biomass was carried out in a series of conical flasks with a volume of $1000 \mathrm{ml}$ each. To this end, these flasks were previously cleaned and $500 \mathrm{ml}$ of previously prepared fermentation medium were introduced into each, then closed with tissue and aluminum foil and autoclaved at $121{ }^{\circ} \mathrm{C}$ for 15 minutes. After cooling the series of conical flasks containing the fermentation media were each inoculated with $10 \mathrm{ml}$ of inoculum containing $10^{9} \mathrm{CFU} / \mathrm{ml}$ of Lactobacillus rhamnosus (IS9). The fermentation was carried out in a batch rotary incubator at $35{ }^{\circ} \mathrm{C}$ and $150 \mathrm{rpm}$ for $48 \mathrm{~h}$. To follow up the process of fermentation, $2 \mathrm{ml}$ of the fermenting medium were taken every $10 \mathrm{~h}$ in order to measure the various kinetic parameters of the fermentation.

\section{Analytical techniques}

The biomass was estimated by measuring the absorbance of the fermentation medium as a function of time. The absorbance of the fermentation medium was measured at 580 $\mathrm{nm}$. The values obtained were correlated with the dry mass of probiotic produced during fermentation. The dry mass of probiotic was estimated by the method of ( $\mathrm{Li} \&$ Mira de Orduña, 2010). Sucrose, the source of carbon was determined by the sucrose Assay Kit (MAK013) (Sigma Aldrich, UK).

\section{Effect of Lactobacillus rhamnosus (IS9) on the infected one-day old chick model}

Chicks not infected with pathogens were obtained from a local farm. They were placed in a wooden cage and were fed according to standard rations. Their watering was done using tap water. Chicks were regularly observed and weighed. A total of 90 uninfected chicks aged one day were arbitrarily divided into 3 groups A, B and C of 30 chicks each. Group A chicks were orally administered by gavage as described by Allen-Vercoe and Woodward (1999) for $24 \mathrm{~h}$ with $10^{9}$ CFU / $\mathrm{ml}$ of Lactobacillus rhamnosus (IS9) suspended in $0.1 \mathrm{ml}$ of sterile water. Whereas those of group B and C were respectively orally dosed by gavage with $10^{5} \mathrm{CFU} / \mathrm{ml}$ of Salmonella Enteridis and Salmonella Typhimurium suspended in $0.1 \mathrm{ml}$ of PBS. For the ages of 1, 7, 14 and 35 days post-inoculation, 7 birds were randomly selected from each of the 3 groups. They were slaughtered and the microbiological analysis of their gastrointestinal tract was performed by the enumeration of Salmonella.

\section{Effect of Lactobacillus rhamnosus (IS9) on the infected 14 days old chick model}

A total of 60 uninfected chicks aged 14 days were arbitrarily divided into 3 groups D, E 
and F of 20 chicks each. Group D chicks were orally administered by gavage as described by Allen-Vercoe and Woodward (1999) for $24 \mathrm{~h}$ with $10^{9}$ CFU / $\mathrm{ml}$ of Lactobacillus rhamnosus (IS9) suspended in $0.1 \mathrm{ml}$ of sterile water. Whereas those in group $\mathrm{E}$ and $\mathrm{F}$ were respectively orally dosed by oral gavage with $10^{5} \mathrm{CFU} / \mathrm{ml}$ of Salmonella Enteridis and Salmonella Typhimurium suspended in $0.1 \mathrm{ml}$ of PBS buffer. For the ages of 1, 714 and 35 days post-inoculation, 7 birds were randomly selected in each of the 3 groups in view of microbiological analyzes.

\section{Enumeration of Salmonella in tissues}

The birds were slaughtered by cervical dislocation. The liver, duodenum, jejunum, ileum, colon and caeca were removed aseptically from each bird and placed separately in a sterile bottle.

Each organ was homogenized in an appropriate volume of PBS buffer so as to have a dilution factor of 1/10. The enumeration of viable Salmonella was carried out by surface seeding on the SalmonellaShigella agar (SS agar) (Liofilchem s.r.l. Bacteriology Products).

Semi-quantitative enumeration of Salmonella was carried out using the semi-quantitative approach of (Smith \& Tucker, 1980). Caeca swabs were taken at weekly intervals from 24 $\mathrm{h}$ after challenge. Swabs were taken from the remaining birds selected at random at each time point. The Salmonella were enumerate on Salmonella-Shigella (SS) agar.

\section{Statistical analysis}

The statistical analysis of the colonization of the different parts of the digestive tract of birds by the Salmonella strains was carried out for the birds which received the oral administration of the probiotic and those which did not receive. Differences were compared in the liver, duodenum etc. using the Mann-Whitney non parametric test.

\section{Results and Discussion}

Production of probiotic biomass and
control of their viability The culture of L. rhamnosus (IS9) strain in the prepared fermenting medium showed growth materialized in Fig. 1 by three main phases. A logarithmic phase (exponential) characterized by an accelerated growth of the strain. This phase was within the first $18 \mathrm{~h}$ of fermentation. During this phase, production of probiotic biomass reached approximately 3.8 $\mathrm{g}$ of dry L. rhamnosus (IS9) cells per liter of fermenting medium. Viability tests using methylene blue showed that about 98-100\% of cells observed after centrifugation and recovery were viable. The production of probiotic biomass was stabilized between 18 and $24 \mathrm{~h}$ after the start of the fermentation. Beyond $30 \mathrm{~h}$, there was a decrease in biomass (Fig. 1). Sucrose, the main carbon source used by the strain L. rhamnosus (IS9) during its growth, was dosed (Fig. 1). This figure shows that the initial concentration of sucrose decreased as time progressed and finally reached about $4 \%(\mathrm{w} / \mathrm{v})$ after $60 \mathrm{~h}$ of fermentation.

Effect of temperature, $\mathrm{pH}$, rotation rate and inoculum size on the production of probiotic biomass

The study of the effect of variation of temperature on the production of probiotic biomass showed that the production was optimal for temperatures between 35 and 40 ${ }^{\circ} \mathrm{C}$ with a maximum at $37^{\circ} \mathrm{C}$. The optimum $\mathrm{pH}$ for the production of biomass were ranged between 5.0 and 4.0. The size of the inoculum influenced the production of biomass. The biomass changed as the concentration of the 
inoculum increased to a maximum (about 3.8 g / 1) when the inoculum concentration was $10^{8} \mathrm{CFU} / \mathrm{ml}$ (Fig. 2). The biomass also increased with the speed of rotation of the rotary incubator (Fig. 3), it reached an optimal value of $3.7 \mathrm{~g} / \mathrm{l}$ when the speed was between $150-200 \mathrm{rpm}$.

In-vitro control of the anti-Salmonella activity of the probiotic biomass produced

The in-vitro control tests performed on the ability to inhibit the growth of Salmonella strains are shown in the Fig. 4. This result confirms that L. rhamnosus (IS9) has the ability to inhibit the growth of several strains of Salmonella. The anti-Salmonella activity of our L. rhamnosus (IS9) was large and comparable to those of some known antibiotics, the inhibition diameters were greater with $S$. Typhimurium compared to $S$. Enteridis.

Effect of predosing birds with $L$. rhamnosus (IS9) on the colonization and persistence of $S$. Enteridis in the one-dayold chick model

Table 1 shows the results of administration of the probiotic strain in infected birds. The animal model used here is the one-day-old chick. These results show the microbial load of the gastrointestinal tract in chicks infected with $S$. Enteridis and those pre-dosed with $L$. rhamnosus. The organs analyzed in this study were: liver, duodenum, jejunum ileum, colon, caeca. The rate of colonization by the pathogenic strain $S$. Enteridis varies from one organ to another and also with the postinoculation duration.

In the liver, one day after inoculation, there was no statistically significant difference $(\mathrm{P}=$ 0.712) between chicks infected with $S$. Enteridis and those infected after pre-dosing with L. rhamnosus (IS9). On the other hand, at the end of the seventh day until the 35th day, there was a significant reduction $(\mathrm{P}<0.05)$ of $S$. Enteridis in the liver of the preassayed chicks with the strain $L$ rhamnosus (IS9). It can also be seen that from the 7th day post-inoculation, the number of salmonellae is almost nil in the liver of the chicks pre-dosed by oral gavage with the probiotic strain, confirming once again the significant suppression of $S$. Enteridis in the liver of chicks given oral gavage of $L$. rhamnosus (IS9).

At the level of the duodenum, the bacterial load is greater than that obtained in the liver. As before, a significant reduction $(\mathrm{P}<0.05)$ of Salmonella in the duodenum of chicks previously administered the probiotic $L$. rhamnosus strain (IS9) was observed. Further microbiological analyzes of the gastrointestinal tract in infected or uninfected chicks show that the colon compared to other organs is richer in microorganisms. All the same, a significant reduction was observed on day 7 post-inoculation and beyond.

Concerning the effect of the probiotic strain (L. rhamnosus IS9) on S. Typhimurium, the results (not shown) were similar to those obtained with $S$. Enteridis. But with a higher rate of reduction.

Analysis of weekly caeca swabs of chicks pre-dosed with L. rhamnosus (IS9) is presented in Figure 5. A significant reduction in salmonellae $(\mathrm{P}<0.05)$ is observed. While the Caecal population of lactobacilli increases.

Probiotics are microbial strains useful to humans and animals. These strains have medical and pharmaceutical interests (Eser et al., 2012; Forssten et al., 2011; Vandenplas et al., 2013; Veldman, 1992; Vyas \& Ranganathan, 2012; Wang et al., 2014; Wasilewski et al., 2015). 
Table.1 Colonization of 1-day-old chick model by Salmonella Enteritidis with and without lactobacilli predose

\begin{tabular}{|c|c|c|c|c|c|c|}
\hline $\begin{array}{l}\text { Days Post- } \\
\text { inoculation }\end{array}$ & Treatment & Tissue Type & $\begin{array}{c}\text { Positive } \\
\text { tissue }\end{array}$ & Mean & SD & P-value \\
\hline 1 & S.ent. alone & \multirow[t]{8}{*}{ Liver } & $7 / 7$ & 1.349 & 0.021 & \\
\hline 1 & S. ent +IS9 & & $5 / 7$ & 1.330 & 0.410 & 0.712 \\
\hline 7 & S.ent. alone & & $7 / 7$ & 3.530 & 0.368 & \\
\hline 7 & S. ent +IS9 & & $0 / 7$ & 0 & 0 & 0.024 \\
\hline 14 & S.ent. alone & & $7 / 7$ & 2.089 & 0.046 & \\
\hline 14 & S. ent +IS9 & & $0 / 7$ & 0 & 0 & 0.031 \\
\hline 35 & S.ent. alone & & $7 / 7$ & 2.292 & 0.020 & \\
\hline 35 & S. ent +IS9 & & $0 / 7$ & 0 & 0 & 0.034 \\
\hline 1 & S.ent. alone & \multirow[t]{8}{*}{ Duodenum } & $7 / 7$ & 2.383 & 0.035 & \\
\hline 1 & S. ent +IS9 & & $3 / 7$ & 1.08 & 0.002 & 0.100 \\
\hline 7 & S.ent. alone & & $7 / 7$ & 3.99 & 0.050 & \\
\hline 7 & S. ent +IS9 & & 0 & 0 & 0 & 0.042 \\
\hline 14 & S.ent. alone & & $2 / 7$ & 2.191 & 0.124 & \\
\hline 14 & S. ent +IS9 & & 0 & 0 & 0 & 0.031 \\
\hline 35 & S.ent. alone & & $3 / 7$ & 5.284 & 0.038 & \\
\hline 35 & S. ent +IS9 & & 0 & 0 & 0 & 0.023 \\
\hline 1 & S.ent. alone & \multirow[t]{8}{*}{ Jejunum } & $7 / 7$ & 1.385 & 0.012 & \\
\hline 1 & S. ent +IS9 & & $1 / 7$ & 1.108 & 0.019 & 0.741 \\
\hline 7 & S.ent. alone & & $6 / 7$ & 4.0466 & 0.0518 & \\
\hline 7 & S. ent +IS9 & & 0 & 0 & 0 & 0.025 \\
\hline 14 & S.ent. alone & & $7 / 7$ & 2.168 & 0.118 & \\
\hline 14 & S. ent +IS9 & & 0 & 0 & 0 & 0.047 \\
\hline 35 & S.ent. alone & & $5 / 7$ & 2.325 & 0.023 & \\
\hline 35 & S. ent +IS9 & & 0 & 0 & 0 & 0.0251 \\
\hline 1 & S.ent. alone & \multirow[t]{8}{*}{ Ileum } & $7 / 7$ & 1.337 & 0.081 & \\
\hline 1 & S. ent +IS9 & & $3 / 7$ & 1.269 & 0.017 & 0.056 \\
\hline 7 & S.ent. alone & & $7 / 7$ & 3.957 & 0.049 & \\
\hline 7 & S. ent +IS9 & & $1 / 7$ & 1.052 & 0.028 & 0.064 \\
\hline 14 & S.ent. alone & & $7 / 7$ & 3.434 & 0.070 & \\
\hline 14 & S. ent +IS9 & & $0 / 7$ & 0.754 & 0.0159 & 0.031 \\
\hline 35 & S.ent. alone & & $5 / 7$ & 4.116 & 0.080 & \\
\hline 35 & S. ent +IS9 & & $0 / 7$ & 0.517 & 0.005 & 0.0123 \\
\hline 1 & S.ent. alone & \multirow[t]{3}{*}{ Colon } & $7 / 7$ & 1.725 & 0.047 & \\
\hline 1 & S. ent +IS9 & & $3 / 7$ & 0 & 0 & 0.341 \\
\hline 7 & S.ent. alone & & $7 / 7$ & 3.090 & 0.024 & \\
\hline
\end{tabular}




\begin{tabular}{|c|c|c|c|c|c|c|}
\hline 7 & S. ent +IS9 & & $1 / 7$ & 1.341 & 0 & 0.316 \\
\hline 14 & S.ent. alone \\
\cline { 4 - 6 } & S. ent +IS9 & $7 / 7$ & 4.160 & 0.05 & \\
\hline 14 & S.ent. alone & 0 & 0 & 0 & 0.017 \\
\hline 35 & S. ent +IS9 & $7 / 10$ & 5.261 & 0.036 & \\
\hline 35 & & $0 / 7$ & 0 & 0 & 0.315 \\
\cline { 3 - 6 } & &
\end{tabular}

\section{Table 1(Continued)}

\begin{tabular}{|c|c|c|c|c|c|c|}
\hline $\begin{array}{l}\text { Days Post- } \\
\text { inoculation }\end{array}$ & Treatment & Tissue Type & $\begin{array}{c}\text { Positive } \\
\text { tissue }\end{array}$ & Mean & SD & P-value \\
\hline 1 & S.ent. alone & \multirow[t]{8}{*}{ Ceaca } & $7 / 7$ & 4.384 & 0.062 & \\
\hline 1 & S. ent +IS9 & & 6 & 0.317 & 0.007 & 0.023 \\
\hline 7 & S.ent. alone & & 7 & 4.805 & 0.051 & \\
\hline 7 & S. ent +IS9 & & $1 / 7$ & 0.532 & & 0.017 \\
\hline 14 & S.ent. alone & & $7 / 7$ & 4.924 & 0.084 & \\
\hline 14 & S. ent +IS9 & & $1 / 7$ & 0.191 & 0.006 & 0.034 \\
\hline 35 & S.ent. alone & & $5 / 7$ & 5.483 & 0.407 & \\
\hline 35 & S. ent +IS9 & & $0 / 7$ & 0.6386 & 0.037 & 0.014 \\
\hline
\end{tabular}

S. ent., Salmonella Enteridis; IS9, Lactobacillus rhamnosus

Fig.1 Time course for the probiotic biomass (Lactobacillus rhamnosus IS9) production and sucrose consumption when fermenting medium used was made of $2 \%(\mathrm{w} / \mathrm{v})$ molasse supplemented with $1 \%(\mathrm{w} / \mathrm{v})$ soya bean flour. Values are an average of three replicates \pm standard deviation

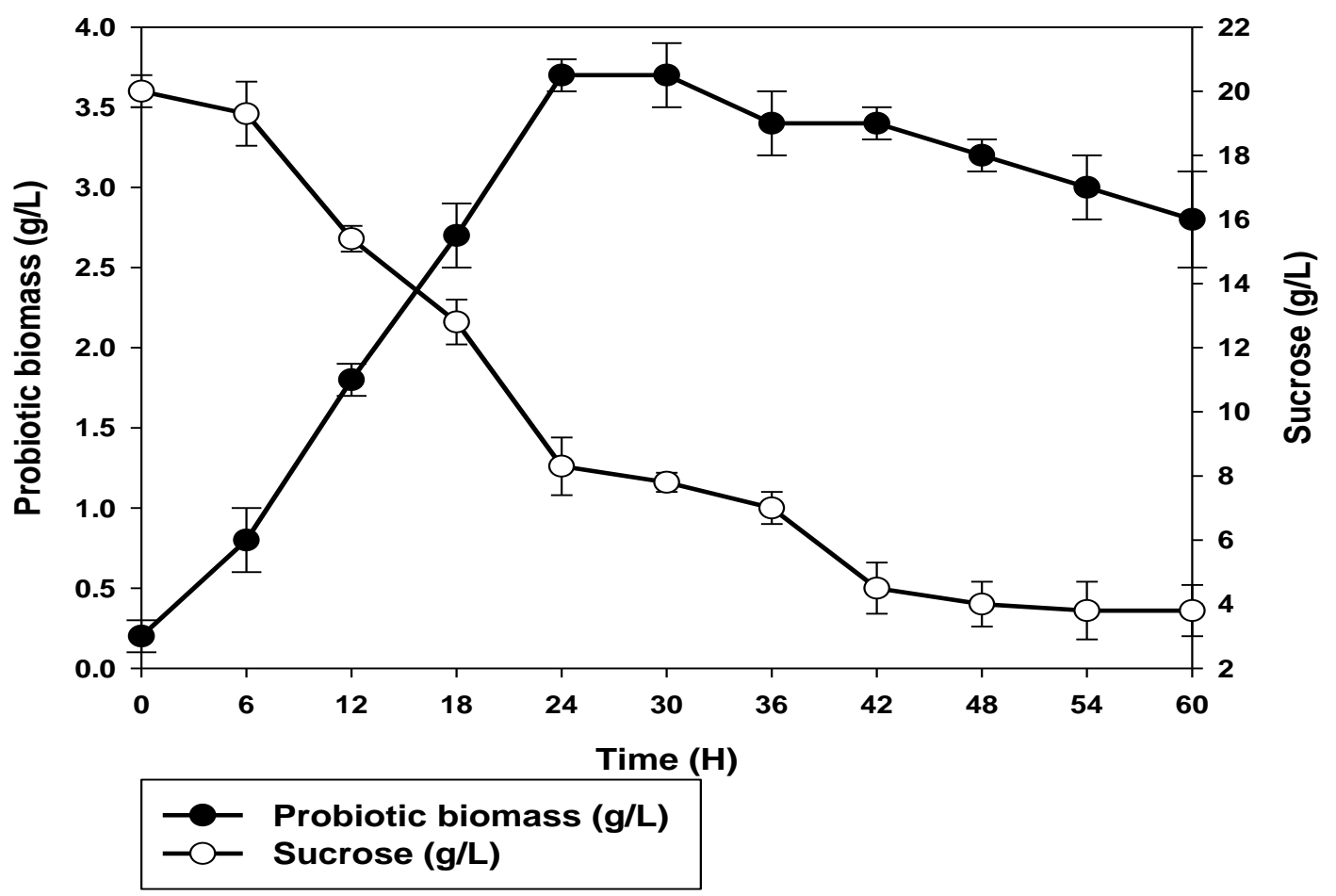


Fig.2 Effect of temperature and $\mathrm{pH}$ on probiotic biomass (Lactobacillus fermentum IS9) production. Values are an average of three replicates \pm standard deviation

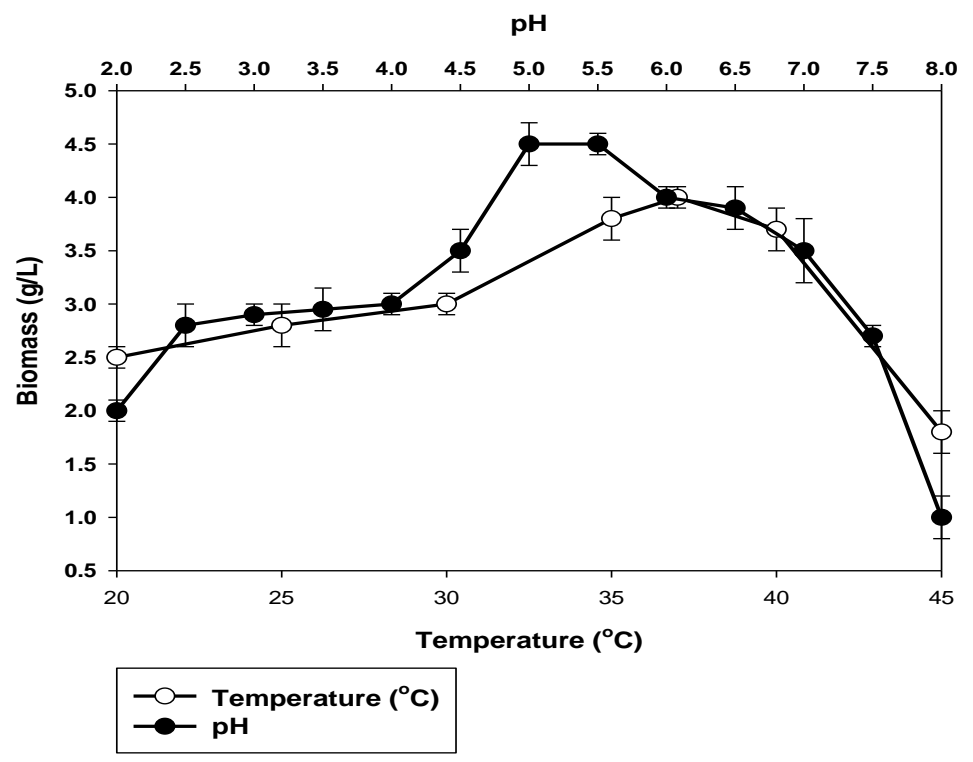

Fig.3 Effect of inoculum concentration and rotation speed of the rotary incubator on probiotic biomass (Lactobacillus rhamnosus IS9) production. Values are an average of three replicates \pm standard deviation

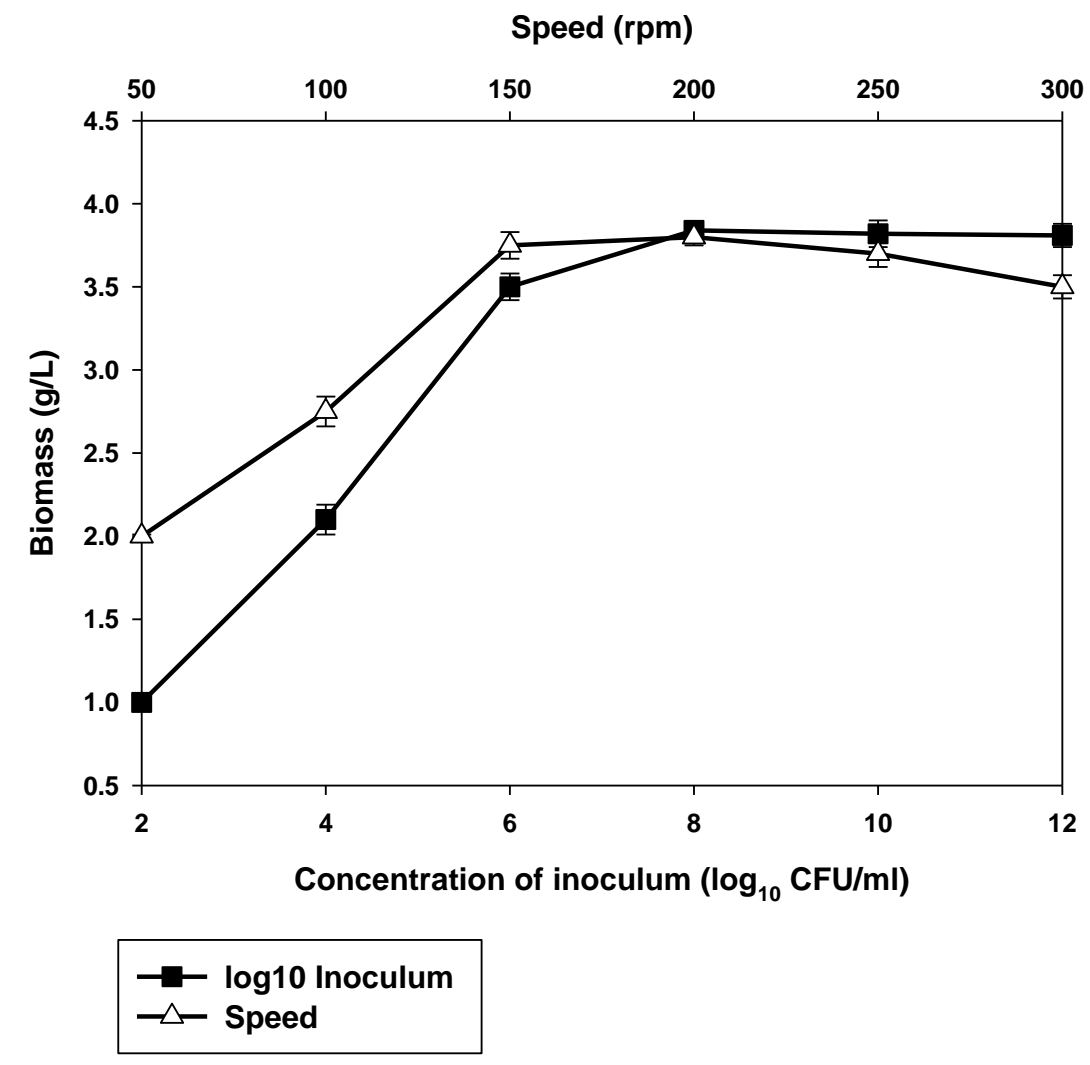


Fig.4 Plate assays for antimicrobial activity of cell free supernatant (CFS) from Lactobacillus rhamnosus (IS9) culture against Salmonella Enteridis and Salmonella Typhimurium after probiotic biomass production and recovery

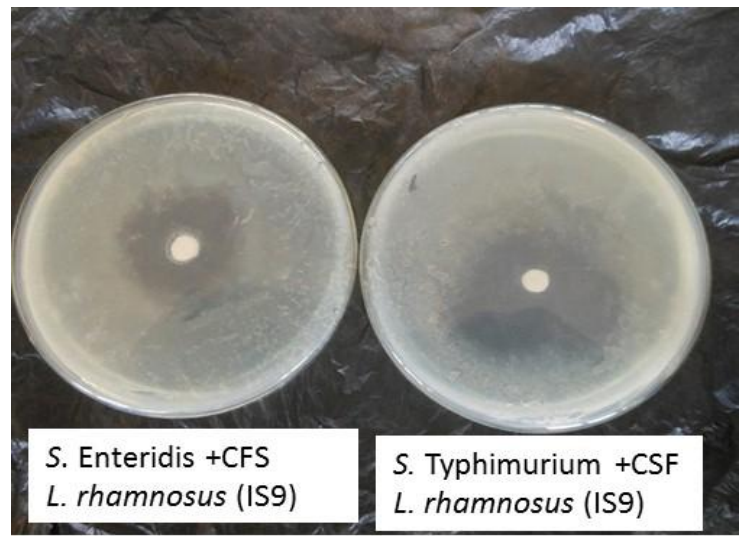

Fig.5 Salmonella and lactobacilli count in caeca swabs from chicks pre-dosed with L. rhamnosus (IS9)

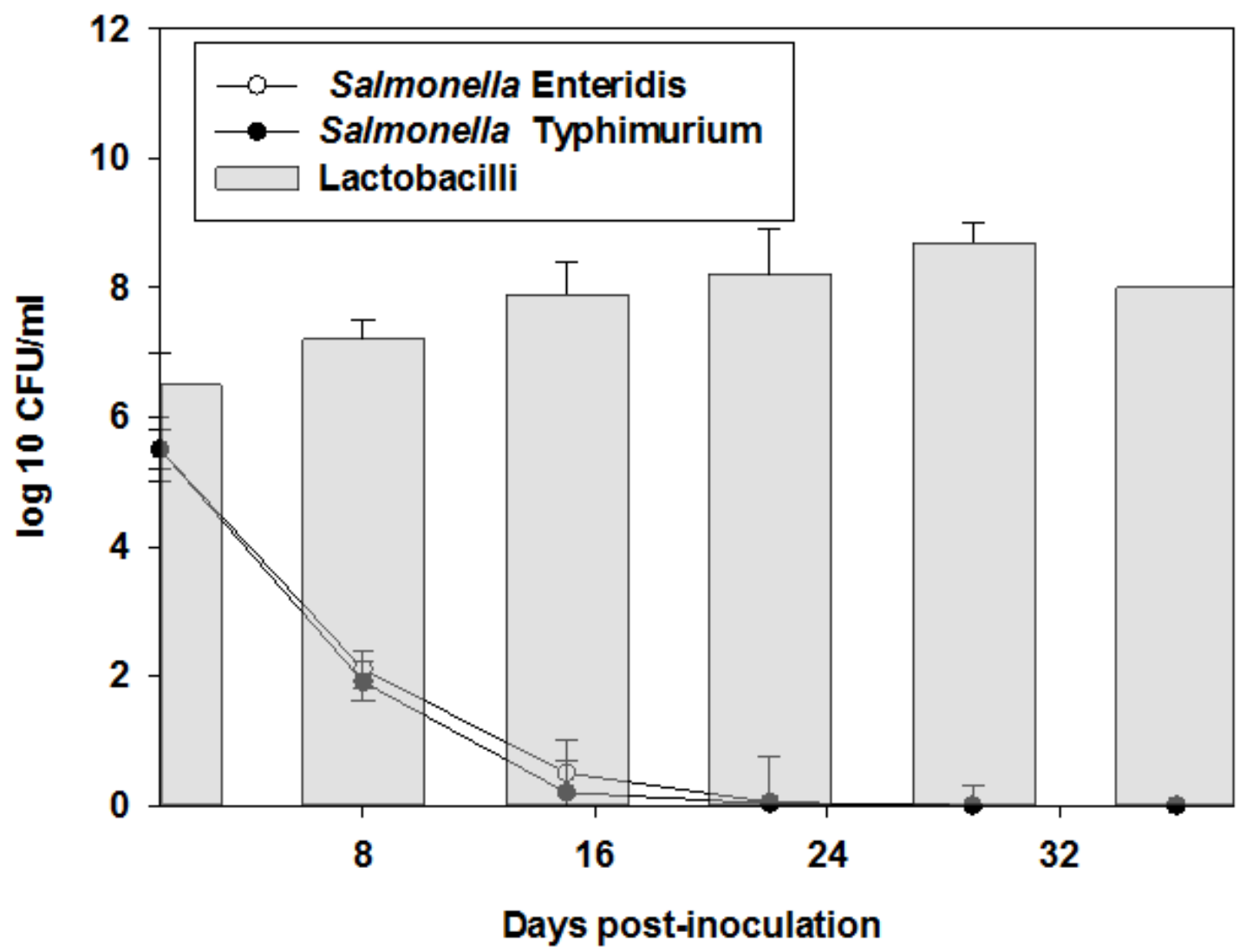


These reasons explain the interest of many works pursued in this research area. As part of our work, we were interested in producing a large probiotic biomass in order to confront it with the occurrence of Salmonella in poultry farming in the South west region of Cameroon. Salmonellosis is one of the most important threats to the poultry industry (Vandeplas et al., 2010). Consumption of raw or uncooked poultry products can induce gastroenteritis (Tsai et al., 2005; Tsiouris, 2016; Vandeplas et al., 2010). The prolonged use of antibiotics in the breeding of poultry generally leads to the development of antibiotic-resistant microbial strains. The use of probiotic microbial strains are now seen as a good approach to the prevention and eradication of salmonella-induced gastroenteritis (Williams et al., 2010; Xie et al., 2015). The effectiveness of a probiotic against a foodborne pathogen depends on the concentration of probiotic germs administered (Salminen et al., 2009; Salminen et al., 2010). The number of viable colonies forming unit (CFU) in a probiotic product is critical for its efficacy against pathogenic strains. Most effective probiotic preparations contain about $10^{10}$ to $10^{12} \mathrm{CFU} / \mathrm{g}$ (Coeuret et al., 2004b). It is therefore important to have a high probiotic biomass in order to make the dosage efficient (Aguirre-Ezkauriatza et al., 2010)

The probiotic biomass of the L. rhamnosus (IS9) strain obtained in our study is comparable to that obtained by AguirreEzkauriatza et al., (2010). These authors obtained a probiotic biomass of about $3.2 \mathrm{~g} / \mathrm{l}$ for the first $20 \mathrm{~h}$ in batch fermentation using an inexpensive fermentation medium composed of goat's milk. Studies conducted by (Schiraldi et al., 2003) show a number of colonies forming a unit of about $1.5 \times 10^{9} \mathrm{CFU}$ $/ \mathrm{ml}$. This value is recommended for probiotic products. Most authors who have worked in this aspect have used milk-based media instead. The peculiarity of our research work was the production of probiotic biomass from a molasse-based medium. Molasses have the characteristic of being cheap in Cameroon, this is one of the reasons that justify the choice of this substrate to obtain an important biomass of L. rhamnosus (IS9). Studies carried out by Salminen and van Loveren (2012), have been consistent with our results. These authors have used low-cost media for the multiplication and production of biomass of bifodobacteria. Kibeom et al., (2013) have developed a cheaper alternative corn and molasses medium for the important growth (biomass production) of Lactobacillus salivarus (L29). In studying the effect of prebiotic on production of probiotic biomass, Csutak (2010), demonstrated the importance of the various food components that can be used for the multiplication of $L$. acidophilus (LA-5) and Bifiodobacterium (BB-12). These few examples show the opportunities to develop a cheaper medium that can be implemented for the industrial production of probiotics.

To return to the anti-Salmonella activity of our L. rhamnosus (IS9) strain, the in-vitro activity is large and comparable to those of some known antibiotics, the inhibition diameters are greater with $S$. Typhimurium compared to $S$. Enteridis.

The strain L. rhamnosus (IS9) presented and in vivo efficacy against salmonella demonstrated by a significant reduction in Salmonella count in gastro-intestinal tract of one-day old and 14-days old pre-dosed chick model challenged with $S$. Enteridis and $S$. Typhimurium. Similar observations have been made by La Ragione and Narbad (2004), these authors showed that L. Johnsonii (F19785) colonized the gastrointestinal tract of poultry which result in reduction of $S$. Enteridis and significant reduction $(\mathrm{P}<0.01)$ of Clostridium perfringens also common in poultry. Tsai et al., (2005) showed the 
antagonistic effect of Lactobacillus strain LAD5 and LF33 against Salmonella (S. Typhimurium) invasion to cultured human intestinal cell line Int 407 and to mouse B ALB/c liver and spleen. Laukova et al., (2015) showed that Enterococcus faecium AL41 administered orally to ostriches led to a significant reduction in coagulase positive and negative Staphylococcus, coliform and pseudomonas like in the gastro intestinal tract of ostriches. Most of the probiotic tested in poultry have been isolated from their gastro intestinal tract (Svetoch et al., 2009) while $L$. rhamnosus (IS9) tested in our study is a palm wine isolate. The used of exogenous or allochthonous bacteria with probiotic properties is not too common in poultry. Whatever their origin, the use of probiotics is very useful in poultry. It could help to reduce the intensive use of antibiotic that cause the development of antibiotic resistant strains. These examples highlighted the possibility of controlling pathogens in poultry using probiotic bacteria.

\section{Acknowledgement}

The authors would like to acknowledge the Biotechnology Unit of University of Buea, Cameroon, for providing facilities for research.

\section{References}

Aguirre-Ezkauriatza, E.J., Aguilar-Yanez, J.M., Ramirez-Medrano, A., Alvarez, M.M. 2010. Production of probiotic biomass (Lactobacillus casei) in goat milk whey: comparison of batch, continuous and fedbatch cultures. Bioresour Technol, 101(8), 2837-44.

Akoachere, J.F., Nicoline, F., Tanih, Ndip, L. M., Ndip R. 2009. Phenotypic Characterization of Salmonella Typhimurium Isolates from Food-animals and Abattoir Drains in Buea, Cameroon. $J$ Health Popul Nutr, 27(5), 612-618.

Allen-Vercoe, E., Woodward, M.J. 1999.
Colonisation of the chicken caecum by afimbriate and aflagellate derivatives of Salmonella enterica serotype Enteritidis. Vet Microbiol, 69(4), 265-75.

Amara, A.A., Shibl, A. 2015. Role of Probiotics in health improvement, infection control and disease treatment and management. Saudi Pharm J, 23(2), 107-14.

Coeuret, V., Gueguen, M., Vernoux, J.P. 2004a. In vitro screening of potential probiotic activities of selected lactobacilli isolated from unpasteurized milk products for incorporation into soft cheese. J Dairy Res, 71(4), 451-60.

Coeuret, V., Gueguen, M., Vernoux, J.P. 2004b. Numbers and strains of lactobacilli in some probiotic products. Int $J$ Food Microbiol, 97(2), 147-56.

Csutak, E. 2010. Effect of various prebiotics on LA-5 and BB-12 probiotic bacteria multiplication, and on probiotic yoghurt production. Acta Univ. Sapientiae, Alimentaria, 3, 35-52.

Eser, A., Thalhammer, F., Burghuber, F., Hogenauer, C., Stockenhuber, F., Wenisch, C., Widhalm, K., Reinisch, W. 2012. [Probiotics for the prevention of antibiotic-induced diarrhea]. $Z$ Gastroenterol, 50(10), 1089-95.

Forssten, S.D., Sindelar, C.W., Ouwehand, A.C. 2011. Probiotics from an industrial perspective. Anaerobe, 17(6), 410-3.

Kibeom, L., Sang-Kee, K., Yun, J.C. 2013. A low-cost Lactobacillus salivarius L29 growth medium containing molasses and corn steep liquor allows the attainment of high levels of cell mass and lactic acid production. Afr J Biotechnol, 12(16), 2013-2018.

Kilonzo-Nthenge, A., Rotich, E., Nahashon, S.N. 2013. Evaluation of drug-resistant Enterobacteriaceae in retail poultry and beef. Poult Sci, 92(4), 1098-107.

La Ragione, R.M., Narbad, A. 2004. In vivo characterization of Lactobacillus johnsonii FI9785 for use as a defined competitive exclusion agent against bacterial pathogens in poultry. Lett appl Microbiol, 38, 197-205.

La Ragione, R.M., Narbad, A., Gasson, M.J., Woodward, M.J. 2004. In vivo 
characterization of Lactobacillus johnsonii FI9785 for use as a defined competitive exclusion agent against bacterial pathogens in poultry. Lett Appl Microbiol, 38(3), 197-205.

Li, E., Mira de Orduña, R. 2010. A rapid method for the determination of microbial biomass by dry weight using a moisture analyser with an infrared heating source and an analytical balance. Lett Appl Microbiol, 50(3), 283-288.

Mappley, L.J., Tchorzewska, M.A., Cooley, W.A., Woodward, M.J., La Ragione, R.M. 2011. Lactobacilli antagonize the growth, motility, and adherence of Brachyspira pilosicoli: a potential intervention against avian intestinal spirochetosis. Appl Environ Microbiol, 77(15), 5402-11.

Mondragon-Parada, M.E., Najera-Martinez, M., Juarez-Ramirez, C., Galindez-Mayer, J., Ruiz-Ordaz, N., Cristiani-Urbina, E. 2006. Lactic acid bacteria production from whey. Appl Biochem Biotechnol, 134(3), 223-32.

Nzouankeu, A., Ngandjio, A., Ejenguele, G., Njine, T., Ndayo, W. 2010. Multiple contaminations of chickens with Campylobacter, Escherichia coli and Salmonella in Yaounde (Cameroon). $J$ Infect Dev Ctries 2010, 4(9), 583-586.

Salminen, S., Collado, M.C., Isolauri, E., Gueimonde, M. 2009. Microbial-host interactions: selecting the right probiotics and prebiotics for infants. Nestle Nutr Workshop Ser Pediatr Program, 64, 20113; discussion 213-7, 251-7.

Salminen, S., Nybom, S., Meriluoto, J., Collado, M.C., Vesterlund, S., El-Nezami, H. 2010. Interaction of probiotics and pathogens--benefits to human health? Curr Opin Biotechnol, 21(2), 157-67.

Salminen, S., van Loveren, H. 2012. Probiotics and prebiotics: health claim substantiation. Microb Ecol Health Dis, 23.

Schiraldi, C., Adduci, V., Valli, V., Maresca, C., Giuliano, M., Lamberti, M., Carteni, M., De Rosa, M. 2003. High cell density cultivation of probiotics and lactic acid production. Biotechnol Bioeng, 82(2),
213-22.

Smith, H.W., Tucker, J.F. 1980. The virulence of Salmonella strains for chickens: their excretion by infected chickens. J Hyg (Cambs), 84, 479-488.

Svetoch, E.A., Eruslanov, B.V., Kovalev, Y.N., Mitsevich, E.V., Mitsevich, I.P., Levchuk, V.P., Fursova, N.K., Perelygin, V.V., Stepanshin, Y.G., Teymurasov, M.G., Seal, B.S., Stern, N.J. 2009. Antimicrobial Activities of Bacteriocins E 50-52 and B 602 Against AntibioticResistant Strains Involved in Nosocomial Infections. Probiotics Antimicrob Proteins, 1(2), 136.

Tatsinkou, F.B., Goghomu, S., Tongwa, M., Ndjouenkeu, R., Cho-Ngwa, F. 2017. Screening for Bacteriocins Producing Probiotic Bacteria from Fermented Sap of Palm Trees (Elaeis Guineesis and Raffia Sudanica): Production and Partial Characterization of Bacteriocins. J Appl Biotechnol Bioeng, 2(1), 1-8.

Tsai, C.C., Hsih, H.Y., Chiu, H.H., Lai, Y.Y., Liu, J.H., Yu, B., Tsen, H.Y. 2005. Antagonistic activity against Salmonella infection in vitro and in vivo for two Lactobacillus strains from swine and poultry. Int J Food Microbiol, 102(2), 185-94.

Tsiouris, V. 2016. Poultry management: a useful tool for the control of necrotic enteritis in poultry. Avian Pathol, 45(3), 323-5.

Vandenplas, Y., De Greef, E., Hauser, B., Devreker, T., Veereman-Wauters, G. 2013. Probiotics and prebiotics in pediatric diarrheal disorders. Expert Opin Pharmacother, 14(4), 397-409.

Vandeplas, S., Dubois Dauphin, R., Beckers, Y., Thonart, P., Thewis, A. 2010. Salmonella in chicken: current and developing strategies to reduce contamination at farm level. J Food Prot, 73(4), 774-85.

Veldman, A. 1992. [Probiotics]. Tijdschr Diergeneeskd, 117(12), 345-8.

Vyas, U., Ranganathan, N. 2012. Probiotics, prebiotics, and synbiotics: gut and beyond. Gastroenterol Res Pract, 2012, 872716.

Wang, S., Zhu, H., Lu, C., Kang, Z., Luo, Y., Feng, L., Lu, X. 2012. Fermented milk 
supplemented with probiotics and prebiotics can effectively alter the intestinal microbiota and immunity of host animals. J Dairy Sci, 95(9), 4813-22.

Wang, Y., Kuo, S., Shu, M., Yu, J., Huang, S., Dai, A., Two, A., Gallo, R.L., Huang, C.M. 2014. Staphylococcus epidermidis in the human skin microbiome mediates fermentation to inhibit the growth of Propionibacterium acnes: implications of probiotics in acne vulgaris. Appl Microbiol Biotechnol, 98(1), 411-24.

Wasilewski, A., Zielinska, M., Storr, M., Fichna, J. 2015. Beneficial Effects of Probiotics, Prebiotics, Synbiotics, and Psychobiotics in Inflammatory Bowel Disease. Inflamm Bowel Dis, 21(7), 1674-82.

Williams, M.D., Ha, C.Y., Ciorba, M.A. 2010. Probiotics as therapy in gastroenterology: a study of physician opinions and recommendations. J Clin Gastroenterol, 44(9), 631-6.

Wouafo, M., Nzouankeu, A., Kinfack, J.A., Fonkoua, M.C., Ejenguele, G., Njine, T., Ngandjio, A. 2010. Prevalence and antimicrobial resistance of Salmonella serotypes in chickens from retail markets in Yaounde (Cameroon). Microb Drug Resist, 16(2), 171-6.

Xie, Z.L., Bai, D.P., Xie, L.N., Zhang, W.N., Huang, X.H., Huang, Y.F. 2015. Intestinal lactic acid bacteria from
Muscovy duck as potential probiotics that alter adhesion factor gene expression. Genet Mol Res, 14(4), 12262-75.

Zhou, H.J., Yin, L., Chen, C.Q., Shi, M.M., Zhang, M.J. 2010. Administration of probiotics reduces bacterial translocation after intestinal transplantation in rats. Transplant Proc, 42(10), 4643-7.

Zivkovic, R. 1999. Probiotics or microbes against microbes. Acta Med Croatica, 53(1), 238.

Zuccotti, G., Meneghin, F., Aceti, A., Barone, G., Callegari, M.L., Di Mauro, A., Fantini, M.P., Gori, D., Indrio, F., Maggio, L., Morelli, L., Corvaglia, L., Italian Society of, N. 2015. Probiotics for prevention of atopic diseases in infants: systematic review and meta-analysis. Allergy, 70(11), 1356-71.

Zuccotti, G.V., Meneghin, F., Raimondi, C., Dilillo, D., Agostoni, C., Riva, E., Giovannini, M. 2008. Probiotics in clinical practice: an overview. J Int Med Res, 36 Suppl 1, 1A-53A.

Zwolinska-Wcislo, M., Brzozowski, T., Mach, T., Budak, A., Trojanowska, D., Konturek, P.C., Pajdo, R., Drozdowicz, D., Kwiecien, S. 2006. Are probiotics effective in the treatment of fungal colonization of the gastrointestinal tract? Experimental and clinical studies. $J$ Physiol Pharmacol, 57 Suppl 9, 35-49.

\section{How to cite this article:}

Bertrand Tatsinkou Fossi, Ekue Nathalia Bonjah and Robert Ndjouenkeu. 2017. Production of Probiotic Biomass (Lactobacillus rhamnosus IS9) against Salmonella sp for Use as a Feed Supplement in Poultry. Int.J.Curr.Microbiol.App.Sci. 6(6): 3286-3298. doi: https://doi.org/10.20546/ijcmas.2017.606.386 